\title{
LA «NUEVA ATENAS» DEL MEDITERRÁNEO. VICENTE BLASCO IBÁÑEZ, CULTURA Y EDUCACIÓN POPULARES EN VALENCIA
} (1890-1931)

Por Luis Miguel LÁzaro Lorente. Valencia: Institució Alfons el Magnànim-CVEI, 2021, 640 páginas. ISBN: 978-84-7822-868-3

Atenas, en el imaginario colectivo, siempre ha sido reivindicada como lugar de ilustración, como la cuna de la democracia o como el germen de todos los humanismos. De ahí que, a la primera de cambio, y en la medida en que alguna ciudad logre ese espíritu ilustrado, recupera el nombre de esa ciudad como la mejor metáfora para explicar sus adelantos. Hay que recordar que tenemos, por lo menos, tres Atenas del Norte: Asturias, Vitoria y un poco más arriba Edimburgo. Para lograr ese título solo tenían que dar cuenta de algunos indicadores de su ilustración: ciudades altamente alfabetizadas, centros de cultura, bibliotecas, museos, importante red de centros escolares, etc. En el caso del libro que comentamos, en el Mediterráneo ya tenemos a la Atenas antigua y original, que vive de su patrimonio histórico cultural, y la nueva Atenas del Mediterráneo, Valencia, como parecía gustarle a Blasco Ibáñez. Para dar cuenta de que el título es merecido, nuestro autor, Luis Miguel Lázaro Lorente, nos narra de una forma magistral esos avatares culturales de una Atenas imaginada y sigue unos itinerarios que bien merecen la pena para explicarnos la cultura y la educación popular en Valencia, a través de un personaje multifacético, como es Vicente Blasco Ibáñez.

Quienes conocen la trayectoria intelectual y bibliografía del autor de esta monografía, encuentran un renovado interés por temas que forman parte de la constelación de preocupaciones y temáticas que han acompañado de Luis Miguel Lázaro en su itinerario intelectual, científico y literario. Tal parece que la figura de Vicente Blasco Ibáñez viene a ser un 
compendio que resume algunos de los temas bien conocidos por nuestro autor. Es decir, Blasco Ibáñez es un dispositivo que despierta y recupera aspectos que tienen que ver con la cultura o la educación popular en el contexto valenciano. De ahí que el background de conocimientos de nuestro autor le permite relacionar unos temas con otros e insertarlos en un discurso coherente que permite entender los avatares del biografiado, la historia de la cultura o de la educación en un contexto determinado. Por lo tanto, se trata de una obra calidoscópica con multitud de miradas sobre una época y un territorio concreto. Esta riqueza que comentamos dificulta la ubicación de la obra en una determinada disciplina académica, pues se trata de cuestiones que afectan a la historia de la educación, pero también de la cultura, de la educación popular y de la historia del libro, de la producción editorial, cuando no de historia de la literatura. Desde esta perspectiva, también cada uno de los capítulos que conforman el libro podría ser un libro nuevo, con su propia autonomía, sobre la escuela laica, la masonería, la educación de adultos, la lectura popular o la edición popular, con un hilo conductor que se llama Blasco Ibáñez.

La obra que comentamos, aparentemente, y por el hecho de introducir en el título de la misma un nombre propio, parecería que se trata de una obra biográfica. No es el caso, aunque aparezcan datos biográficos por doquier. Se trata de otra forma de acercarse a un personaje y a su contexto político, social y cultural, teniendo siempre presente el ámbito de la educación en un sentido amplio. Por lo tanto, se equivocaría quien espere que el objeto del libro es una biografía al uso de Blasco Ibáñez. En este sentido, el título de la obra deja las cosas bien claras; es decir, se habla de un personaje, de Valencia y de la cultura y la educación popular, en un periodo determinado de la historia, pero no solamente de ello. Lo atractivo de la obra es que se abre a multitud de dimensiones, donde Blasco Ibáñez actúa como un dispositivo que logra engarzar todas las piezas del puzle.

Por otra parte, también se equivocaría quien pretenda encontrar en la obra un capítulo de la historia local de la educación valenciana. No es el caso, aunque inevitablemente en el contexto valenciano están presente todas las actividades llevadas a cabo por el ilustre escritor valenciano. Al igual que en la literatura, se puede estar hablando de un barrio, o de una ciudad y, en ese espacio histórico, detectar todas las claves de los procesos educativos o culturales del universo. De esta manera se entiende la 
mirada valenciana a las nuevas aportaciones culturales y educativas que se producen a partir de los finales del siglo XIX y primer tercio del XX; periodo suficientemente conocido de la historia de la educación en España. Además, queda enriquecido al centrar parte de sus análisis en la actividad cultural y educativa de un movimiento republicano, en el que perviven rasgos de las corrientes más innovadoras en educación, desde el anarquismo, la masonería, o la renovación pedagógica del libre pensamiento, como se aprecia en cada uno de los capítulos. Las fuentes primarias y la bibliografía utilizadas nos dan cuenta de las reformas más importantes llevadas a cabo, resaltando los temas más relevantes de la historia de la educación: la alfabetización, la reforma curricular, los procesos de secularización y las relaciones Iglesia-Estado, etc. Se trata, como tantas veces se ha puesto de manifiesto, de un proceso de modernización que, de manera distinta y a diferentes ritmos, se produjo en España en esa época.

Otro de los méritos de la obra que comentamos es la capacidad del autor para contextualizar al personaje y a las diferentes actividades que analiza en un marco no únicamente español, sino europeo, cuando no mundial. En este sentido, se aprecia la otra gran pasión de Luis Miguel Lázaro como es la educación comparada. Para muestra un botón: en un momento determinado de la obra, nuestro autor recurre a una extensa nota a pie de página (de las 1898 que tiene el texto) para explicarnos los procesos de política educativa que se estaban desarrollando en el contexto europeo (ver páginas 52-53) donde, recurriendo a la comparación, nos informa de la situación de la enseñanza de la religión católica en Europa, reforzando así su argumentación. Asimismo, son de gran valor las aclaraciones terminológicas de los problemas claves de la época, como escuela neutra, escuela libre, escuela laica o escuela racionalista y lo hace contextualizándolo en los debates de la época y no como mero recurso didáctico. En este sentido, las polémicas que suscitaron estas concepciones escolares quedan perfectamente comprensivas en las discusiones políticas.

En cuanto al contenido y a la estructura de la obra, ya hemos señalado que cada capítulo parece tener una autonomía propia y, al igual que ocurre con la célebre obra Rayuela de Julio Cortázar, puede leerse en el orden que se prefiera, pues se trata de un conjunto de partes que completan el puzle perfectamente ensamblado. Pero también habría que destacar la introducción de la obra, plagada de extensísimas notas a pie de página, en la que el autor nos ofrece desde un estado de la cuestión a las claves más relevantes 
que se van a encontrar en los capítulos que la componen. La lectura del índice ya es como un menú de la nueva cocina, donde se encuentran frases evocativas que funcionan como lemas o metáforas para describir el contenido de cada capítulo. Diríamos que es una forma muy francesa de nombrar, a través de palabras, las cosas a las que se refiere. Aquí van el conjunto de títulos de los capítulos: 1. «Los emisarios de Belcebú. La escuela laica como alternativa social y pedagógica», 2. «El sigilo de los Venerables Hermanos. Masonería, librepensamiento, republicanismo y educación», 3. "Una escuela laica vale por todos los casinos. La educación en el proyecto político y en la práctica del republicanismo valenciano», 4. «La educación de adultos en el proyecto de la educación popular del republicanismo valenciano», 5. "El pan del alma. Vicente Blasco Ibáñez y la cultura popular» y 6. «La vraie bombe c'est le livre. La prensa y el libro como poderosos medios de educación popular».

Detrás de cada uno de esos títulos se señalan una serie de epígrafes que montan todo un andamiaje de lo que se pretende explicar con respecto a las temáticas que se van abordando. En el primer capítulo, el foco está centrado en la escuela en todas sus diversas concepciones del momento sobre la escuela pública o privada, pero también laica y neutra, y la renovación pedagógica. No podemos olvidar que nuestro autor conoce bien el tema, pues ya lo había trabajado en otras colaboraciones sobre la educación de Ferrer i Guardia. Se trata, por lo tanto, de recuperar un debate sobre algo que ahora llamaríamos el derecho a la educación, pero que en aquella época se dirimía en la defensa de la enseñanza pública a cargo del Estado. Aquí es donde cobran sentido las aportaciones republicanas por la defensa de una escuela pública y laica. Las referencias tanto a la política educativa francesa como al desarrollo de la Escuela Moderna son ejemplos que se constituyen como referencias para poder plantear una reforma de la escuela, reconociendo los límites de esa propuesta ante un panorama adverso o las dificultades de los procesos de secularización.

Si era necesario este itinerario para comprender los planteamientos republicanos sobre la escuela desde finales del siglo XIX hasta la Segunda República, también lo es el segundo capítulo sobre la masonería, pues tanto una concepción de la escuela desde el republicanismo, como la perspectiva masónica de la educación, son dos pilares sobre los cuales podemos comprender la trayectoria política y literaria de Blasco Ibáñez. 
Cabe recordar nuevamente que este acercamiento al tema no es nuevo en la obra de Luis Miguel Lázaro, dada su querencia a trabajar sobre la masonería, el libre pensamiento o la educación racional. En este sentido su acercamiento al tema no es meramente teórico, sino estudiando el nacimiento de las primeras escuelas laicas valencianas, en colaboración con la masonería, ya que la Logia Valenciana trabajó a favor de la enseñanza laica. Ciudades como Alicante o Valencia ya conocieron iniciativas inspiradas en los principios educativos de la masonería. Si bien es cierto que Blasco Ibáñez solo perteneció a la masonería hasta 1895, también lo es su defensa de sus planteamientos. Nuestro autor reconoce que estas iniciativas fueron limitadas y no exentas de las polémicas del momento. No obstante, la seña de identidad del republicanismo valenciano se sostenía sobre el anticlericalismo, como el mismo Blasco Ibáñez señalaría en un mitin en 1907, con motivo de las elecciones a Cortes: "Nuestra principal bandera es la del anticlericalismo»(p. 107). Postura que defendería permanentemente, si el objetivo era transformar la sociedad a través de la educación de los niños. La responsabilidad de los atrasos de la educación en España se debía, como nos recordará insistentemente, a la educación católica, de ahí su anticlericalismo.

Otra de las facetas que complementan el pensamiento pedagógico de Blasco Ibáñez y su actividad política en el ámbito educativo es la defensa del proyecto del republicanismo valenciano. El vigor y la fuerza argumentativa del escritor valenciano se convirtió en un estandarte que abarca todo el primer tercio del siglo XX, desde que en 1901 se presentara el programa del republicanismo blasquista al Ayuntamiento de Valencia en defensa de la educación popular. En este momento, nuestro autor se despacha con un capítulo sobre lo que se denomina «notas sobre el panorama de la educación en Valencia, 1899-1936» que ocupa unas 175 páginas. No hace falta subrayar que se trata de un auténtico capítulo de historia local de la educación en Valencia, pero centrada en las escuelas laicas de los casinos. Para ello, previamente, se ha tratado los planes de la política municipal o la situación de la escasez de escuelas o el analfabetismo. En realidad, se trata de ofrecer una cartografía escolar de las escuelas laicas en el contexto valenciano, su vinculación a los casinos o a las agrupaciones republicanas de la ciudad de Valencia, además de otras escuelas de la provincia. Para completar este panorama, nuestro autor dedica unas páginas a la situación del magisterio de dichas escuelas y 
sus intentos de organización. Para comprender el alcance de estas modalidades de enseñanza, se refiere asimismo a los espacios de sociabilidad, muy vigorosos en aquella época, sobre todo entre las clases populares, ya fuesen asociaciones, casinos círculos o ateneos. En este caso, los casinos eran esos espacios de política, ocio y educación, aunque no todos los casinos disfrutaban de una escuela laica.

Si bien todas las actividades acerca de la educación podían llevar una influencia difusa de Blasco Ibáñez, en el caso de la Universidad Popular de Valencia, 1903-1928, lleva su sello de iniciativa personal. Como no podía ser de otra manera, nuestro autor nos vuelve a contextualizar dicha iniciativa, en este caso en relación con la trayectoria de la educación popular, desbrozando el terreno en el cual esa experiencia va a florecer. Así, las aportaciones y las preocupaciones por la formación profesional están en la base de una educación de adultos que capacite a los obreros para un futuro profesional. Pero también forman parte de ese orden de preocupaciones las soluciones que se han ido desarrollando en Francia, aunque las referencias a este ámbito de la educación nuestro autor las amplíe hasta Bélgica, Italia, Portugal, Argentina, Brasil o México (p. 314). En definitiva, el modelo que mejor satisfacía la formación de las clases populares era el de la universidad popular. En este cuarto capítulo, por lo tanto, se centra en el análisis histórico pormenorizado de esa universidad popular desde sus inicios en 1903 hasta su desaparición en 1928, debido a conflictos personales. A lo largo de esos años vamos conociendo los avatares por los que pasó desde la acogida del proyecto, las preocupaciones y diferentes concepciones de la educación entre el profesorado y el obrerismo, o las limitaciones pedagógicas del mismo proyecto. Esta experiencia educativa es un buen ejemplo de las soluciones que surgieron en esa época para promocionar la educación de adultos.

En ese ámbito de proyectos y experiencias docentes o de formación popular, al margen del sistema educativo, el capítulo quinto está dedicado a la lectura popular. Aquí nuevamente nuestro autor recurre a sus recursos para contextualizar el alcance de la Biblioteca popular de la Casa del Pueblo de Valencia. No contento con analizar los pormenores de la misma, nos lleva a conocer la aparición de las bibliotecas populares en Europa y Estados Unidos, para posteriormente centrarse en el nacimiento de las bibliotecas populares en España y su situación en el primer tercio del siglo XX. Esta excursión por otros territorios nos permite 
reconocer la importancia y el alcance de estas iniciativas no formales en educación. Queda claro que esta Biblioteca popular valenciana es una iniciativa republicana de Blasco Ibáñez, ligada a una tradición de defensa de la formación obrera. La situación del número de bibliotecas, tanto fijas como circulantes, en el País Valenciano fue importante. El análisis de los fondos de libros que poseía, demuestra la amplia presencia de la literatura, frente a otras temáticas. Desde luego se trata de un capitulo interesante para conocer los hábitos lectores y el uso de las bibliotecas. Las tablas que acompañan el texto sobre los servicios que prestaba la biblioteca en las obras servidas, son un buen capitulo para la historia de la lectura popular.

Para completar esta visión general sobre las actividades desarrolladas en el ámbito cultural valenciano y a iniciativa de Blasco Ibáñez, el último capítulo está dedicado al mundo editorial y del libro. Para ello, nuestro autor se dedica a los avatares de la labor educadora a través de «F. Sempere y Cia., Editores» y de la editorial «Prometeo». La implicación de Blasco Ibáñez en ambas editoriales abarca la colaboración con las mismas y la publicación en ellas de una parte relevante de su obra, durante un periodo importante de tiempo. Este extenso capítulo de la obra de Lázaro puede formar parte de una historia de la literatura y de la producción editorial. A través de sus páginas transcurre la vida y vicisitudes de personajes, escritores y propietarios de editoriales. También los entresijos de las publicaciones, la apertura de mercados editoriales en España, las traducciones de obras, etc. Es decir, un complejo mundo de promoción de mercados culturales y de proyectos encaminados a promover la educación popular.

Como hemos señalado, la obra que estamos comentando rebasa la adscripción a cualquier disciplina académica, adentrándose en un campo cada vez más requerido a los autores como es la interdisciplinaridad. Tal parece que esta obra podría haber estado escrita por un experto en historia de la cultura, de la lectura o del mundo editorial, pero también en historia local y en historia de la educación. De todo ello podemos encontrar en la obra, escrita con un rigor académico cada vez más escaso en la historiografía reciente. Así pues, no podemos más que señalar el interés que tiene la obra, ya que articula alrededor de un escritor, político y animador cultural, que se diría ahora, todo un entramado que nos permite conocer, contextualizar y comparar una serie de fenómenos en 
torno a un conjunto de temas que tienen que ver con la cultura y la educación de una época relevante de la historia de Valencia, pero también de España y Europa. Su lectura es altamente recomendable no solo para conocer una parte de la historia, sino para encontrar estrategias de producción científica renovadora.

Paulí Dávila Balsera Universidad del País Vasco/ Euskal Herriko Unibertsitatea pauli.davila@euh.eus 